\title{
Perancangan furnitur berbasis upcycling waste material batu alam
}

\author{
Gavrila Averina Tirtawijaya, ${ }^{1}$ Yusita Kusumarini, ${ }^{2 *}$ Filipus Priyo Suprobo ${ }^{3}$ \\ ${ }^{1,2}$ Program Studi Desain Interior, Universitas Kristen Petra, Surabaya, Indonesia \\ ${ }^{3}$ Program Studi Arsitektur, Universitas Widya Kartika, Surabaya, Indonesia
}

\begin{abstract}
The use of natural stone in the interior industry is often under-estimated and inefficient. So that unknowingly this causes a lot of waste material from the remaining cutting slabs or stone slabs. Even though if it is reviewed, natural stone waste material has the potential to be recycled into interior products with high aesthetics. In this design the authors collaborate with PT. Gajah Mada Sukses Trinity which is domiciled in Sidoarjo, East Java. This design aims to understand the characteristics of waste material and upcycling techniques that can be applied to highlight its uniqueness. The results of the design in the form of 3 sets of interior product design consisting of coffee tables, side tables, credenza, and console tables, 3 product realization consisting of 2 coffee tables and 1 side table, brands for products \& media promotion, and several alternatives compilation of natural stone waste material into mosaic-shaped sheets. This design proves that natural stone waste materials can be reprocessed by upcycling techniques into high-quality interior products.
\end{abstract}

Key words: natural stone, upcycling, waste material, mosaic

\begin{abstract}
Abstrak
Penggunaan batu alam dalam industri interior seringkali kurang diperhitungkan dan tidak efisien. Sehingga tanpa disadari hal ini menyebabkan banyaknya waste material dari sisa pemotongan slab atau lembaran batu tersebut. Padahal jika ditinjau kembali, waste material batu alam berpotensi untuk diolah kembali menjadi produk interior dengan estetika yang tinggi. Dalam perancangan ini penulis bekerjasama dengan PT. Gajah Mada Sukses Tritunggal yang berdomisili di Sidoarjo, Jawa Timur. Perancangan ini bertujuan untuk memahami karakteristik waste material serta teknik upcycling yang dapat diterapkan untuk menonjolkan keunikannya. Hasil perancangan berupa 3 set desain produk interior yang terdiri dari coffee table, side table, credenza, dan console table, 3 buah realisasi produk yang terdiri dari 2 buah coffee table dan 1 side table, brand untuk produk \& media promosinya, serta beberapa alternatif penyusunan waste material batu alam menjadi lembaran berbentuk mosaik. Perancangan ini membuktikan bahwa waste material batu alam dapat diolah kembali dengan teknik upcycling menjadi produk interior berkualitas tinggi.
\end{abstract}

Kata kunci: batu alam, upcycling, waste material, mosaik

\section{Pendahuluan}

Dalam dunia desain interior terdapat berbagai jenis material yang sangat beragam dan terus berkembang. Terutama karena adanya perkembangan teknologi yang memungkinkan pengaplikasian berbagai jenis material pada ruangan maupun produk interior. Salah satunya yaitu material batu alam, material yang saat ini digemari dan banyak digunakan oleh masyarakat di Indonesia. Bahkan saat ini pengaplikasiannya tidak hanya terbatas untuk eksterior saja, namun telah berkembang dan juga dapat diaplikasikan pada mebel maupun produk dekoratif interior. Produk-produk berbahan batu alam memiliki daya tahan yang baik karena sifatnya kuat dan kaku. Kualitasnya juga terjaga, sehingga mampu meminimalisir biaya perawatan maupun penggantian. Selain itu batu alam juga memiliki keunggulan yaitu karakteristik coraknya yang berbeda-beda antara satu jenis dengan yang lain, sehingga terkesan eksklusif dan berkelas. Batu alam juga dapat memberi kesan natural, elegan, dan mewah pada suatu ruang maupun produk interior. Namun sayangnya batu alam bukan merupakan material ramah lingkungan dan tidak sustainable

\footnotetext{
* Corresponding author Tel : +62-812-316-8156 ; e-mail : yusita@petra.ac.id
} 
karena material ini berasal dari sumber daya alam yang tidak dapat diperbaharui dan ketersediaannya akan semakin menipis dari hari ke hari. Bahkan ada batu jenis tertentu yang tergolong langka karena terbentuk dari fosil atau yang sering disebut petrified wood (Andreani \& Prasetya, 2019) Selain itu proses pengolahannya dari bongkahan hingga menjadi lembaran (slab) juga kurang memenuhi efisiensi energi (membutuhkan mesin khusus, dll). Dalam industri interior, penggunaan batu alam seringkali kurang diperhitungkan dan tidak efisien. Sehingga tanpa disadari hal ini menyebabkan banyaknya waste material dari sisa pemotongan slab atau lembaran batu yang diolah menjadi produk interior. Waste material tersebut akhirnya terbuang dan tidak digunakan lagi, walaupun sebenarnya masih dapat diolah menjadi suatu produk yang fungsional.

Di Sidoarjo, Jawa Timur terdapat salah satu perusahaan yang bergerak sebagai pemasok batu alam sekaligus produsen produk interior berbahan dasar batu alam. Perusahaan itu ialah PT. Gajah Mada Sukses Tritunggal, dimana perusahaan ini juga mengalami permasalahan mengenai penumpukan waste material batu alam (Gambar 1). Mereka memiliki ketertarikan dalam mengembangkan pengolahan waste material batu alam menjadi elemen maupun produk interior.

Melihat situasi dan peluang yang ada, muncul gagasan untuk melakukan perancangan produk berbasis metode upcycling waste material batu alam. Waste material tersebut akan diolah menjadi produk interior (furnitur) sehingga tidak terbuang dan memiliki nilai guna. Tujuannya adalah untuk memberikan alternatif ide baru dalam pemanfaatan waste material batu alam menjadi produk interior.

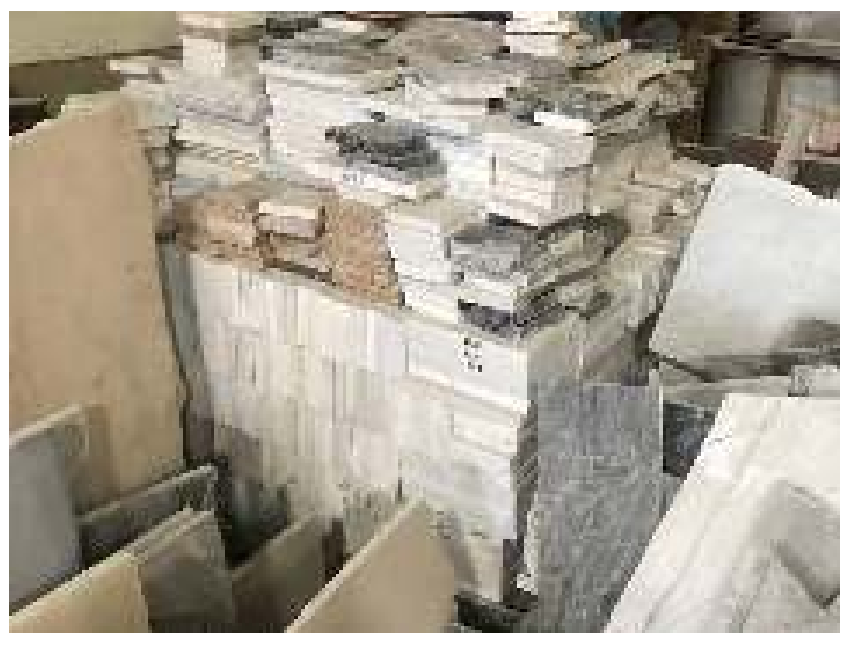

Gambar 1. Waste material batu alam pada PT. Gajah Mada Sukses Tritunggal
Waste material yang semula tidak terpakai dan menumpuk ini akan diolah serta ditingkatkan kualitasnya dengan berdasar dengan prinsip-prinsip upcycling. Pada akhirnya, perancangan produk ini akan berkontribusi dalam membantu mengurangi penumpukan waste material batu alam, serta diharapkan dapat membuka peluang pasar yang baru pula bagi perusahaan terkait.

\section{Metode}

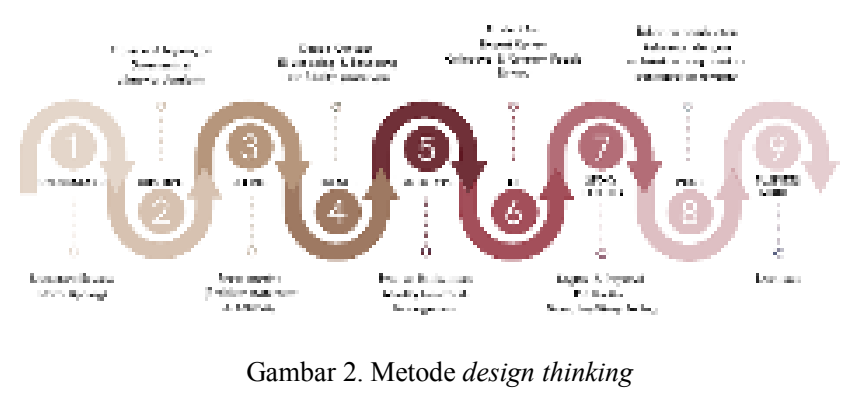

Metode perancangan yang digunakan adalah metode design thinking dengan 9 tahap perancangan, yaitu understand, observe, define, ideate, prototype, test, story telling, pilot, dan business model (Gambar 2). Tahap yang pertama adalah tahap understand. Tahap understand merupakan tahapan pengumpulan dan pemahaman data serta fakta sebagai materi analisa perumusan masalah. Pada perancangan ini digunakan beberapa metode untuk mengumpulkan data, seperti: (a) Literature review, dan (b) Typology review. Tahap berikutnya adalah tahap observe. Tahap observe merupakan tahapan pendalaman pemahaman berkaitan dengan objek yang akan dirancang. Pada perancangan ini digunakan beberapa metode untuk lebih mendalami dan memahami objek perancangan, seperti: (a) Observasi lapangan, (b) Dokumentasi, dan (c) Material analysis. Tahap ketiga adalah tahap define. Tahap define ini merupakan tahapan pengelompokan dan analisis temuan data hasil dari pengumpulan data yang dilakukan pada tahap understand dan observe (Plattner, 2010). Pada tahap ini, data-data tersebut dijabarkan, saling disandingkan satu sama lain, hingga ditemukan keterkaitannya. Pada perancangan ini digunakan metode Programming (problem statement \& solution) untuk mengkorelasikan temuan data pada tahap-tahap sebelumnya. Selanjutnya, tahap ideate. Pada tahap ideate ini, akan dirumuskan ide-ide yang akan menjadi landasan untuk membuat prototype dan menjadi solusi-solusi yang inovatif (Plattner, 2010). Pada perancangan ini diterapkan beberapa metode untuk menghasilkan ide / gagasan yang banyak, yaitu: 
(a) Design Concept, (b) 3D modeling \& rendering, (c) Schematic design, dan (d) Low-fidelity prototype.

Tahap kelima, yaitu prototype, merupakan tahapan pembuatan model purwarupa yang dapat dilihat dan dirasakan, sehingga dapat diketahui kekurangan ataupun kelebihan dari model yang dibuat (Plattner, 2010). Pada perancangan ini digunakan beberapa metode untuk merealisasikan gambar kerja yang telah dibuat pada tahap sebelumnya, menjadi produk interior berbasis upcycling waste material batu alam 1:1, seperti: (a) Product realization, dan (b) Quality control \& management.

Tahap berikutnya adalah tahap test yang merupakan tahapan untuk menguji (mengevaluasi) dan mendapatkan umpan balik dari masyarakat umum sehingga dapat mengetahui kelebihan dan kekurangan dari produk yang dibuat (Plattner, 2010). Hasil evaluasi tersebut selanjutnya akan digunakan sebagai acuan untuk melakukan pembenahan maupun pembaharuan dalam meningkatkan kualitas produk. Pada perancangan ini digunakan beberapa metode untuk mendapatkan umpan balik, seperti: (a) Product test, (b) Expert review, (c) Colleague \& common people review, (d) Market test.

Selanjutnya tahap story telling yang merupakan tahapan pembuatan cerita dari perancangan yang dihasilkan, manfaat serta kontribusinya yang dapat dirasakan oleh khalayak umum yang melihat hasil perancangan ini (Plattner, 2010). Metode yang digunakan antara lain: (a) Digital \& physical publication, dan (b) Narrative story telling.

Tahap kedelapan yaitu tahap pilot. Tahap ini merupakan tahapan pembuatan kebaruan yang belum pernah dilakukan sebelumnya, sehingga perancangan ini dapat diulangi di tempat lain dan khususnya di PT. Gajah Mada Sukses Tritunggal, dengan melakukan penyesuaian-penyesuaian tertentu (Plattner, 2010).

Tahap terakhir, yaitu tahap business model, adalah tahapan pembuatan sebuah model bisnis berkelanjutan yang tidak hanya berorientasi pada aspek ekonomi saja tetapi juga ke aspek sosial atau kultural (Plattner, 2010). Metode yang akan digunakan adalah metode branding dan business model canvas.

\section{Furnitur}

Furnitur adalah salah satu sarana fungsional yang menjadi pelengkap dan pengisi ruang dalam kaitannya dengan penciptaan suasana dan pemenuhan kebutuhan aktivitas pemakai. Furnitur harus bermanfaat dan memberikan nilai guna yang nyaman, serta memenuhi fungsi-fungsi khusus yang menyumbangkan karakter visual dari suatu tatanan interior (Wardani, 2010). Hal yang harus diperhatikan dalam perancangan furnitur antara lain: (a) Kekuatan \& stabilitas untuk mendukung benda yang digunakan, (b) Ukuran, bentuk, dan tinggi di atas lantai yang benar dan sesuai dengan penggunaan yang dimaksudkan, dan (c) Konstruksi dari material yang tahan lama.

\section{Metode upcycling}

Upcycling dapat didefinisikan sebagai usaha untuk mengolah sampah dan mengubahnya menjadi produkproduk dengan nilai kualitas yang lebih tinggi dari material asalnya, tanpa perlu dibongkar, diuraikan, ataupun diberi treatment khusus selama proses transformasi tersebut (Sinai, 2017). Proses ini berkaitan dengan rekreasi bahan-bahan bekas untuk dijadikan suatu produk dengan fungsi yang baru tanpa harus mengeluarkan banyak biaya. Berbeda dengan metode Recycling yang membutuhkan banyak energi selama prosesnya untuk menghancurkan material dan mengubahnya menjadi material dengan kelas yang lebih rendah, metode Upcycling merupakan metode yang sangat hemat energy (Gambar 3). Beberapa kelebihan upcycling antara lain: (a) Sustainability, (b) Environmental wise, dan (c) Creative approach (Ali, 2013).

Dalam penerapan metode upcycling perlu mempertimbangkan beberapa faktor, yaitu: (a) Tipe material, (b) Keawetan, (c) Fungsi, dan (d) Nilai estetika (Ali, 2013). Selain itu juga terdapat prinsip regenerasi dalam upcycling yang dijadikan landasan dalam perancangan ini, antara lain: (a) Prinsip penguatan nilai, (b) Prinsip tanpa sisa, (c) Prinsip durabilitas dan lingkungan, (d) Prinsip kontrol biaya, dan (e) Prinsip estetika masyarakat (Noorwatha, 2017).

Pendekatan upcycle dalam pemanfaatan limbah yang digunakan dalam perancangan ini mengadopsi proses perancangan menggunakan metode kualitatif

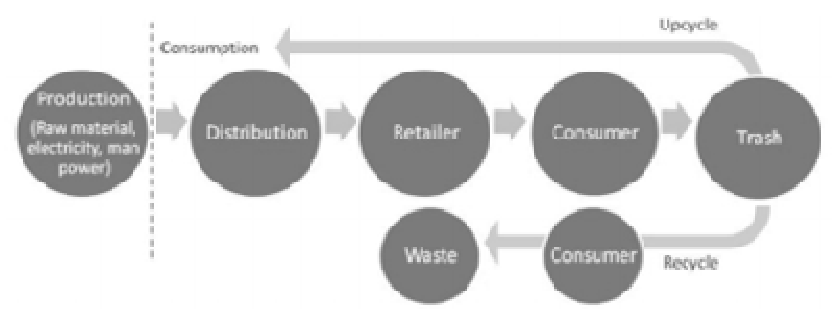

Gambar 3. Skema upcycling serta perbedaannya dengan recycling

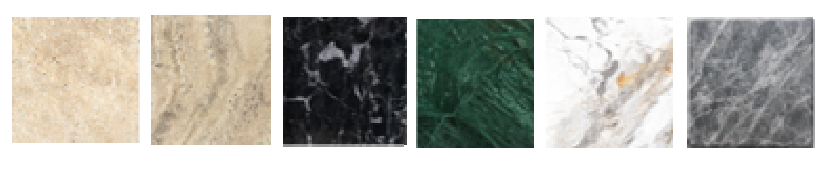

Gambar 4. Beberapa contoh corak batu alam 
yang diproseskan melalui beberapa tahapan yang pernah dilakukan dalam mengolah limbah kayu (Sutanto, Jessica, 2017), diantaranya adalah tahapan discovery-interpretation-ideation-experimentationevolution-implementation.

Pada tulisan ini, objek yang di-upcycling adalah waste material batu alam. Batu alam yang dimaksud merupakan semua bahan yang menyusun kerak bumi dan merupakan suatu agregat mineral-mineral yang telah mengeras akibat proses secara alami seperti membeku, pelapukan, mengendap dan adanya proses kimia. Batu alam memiliki daya tahan yang tidak perlu dipragukan lagi. Selain itu perawatannya juga mudah dan memiliki keindahan warna, corak, serta teksturnya yang kaya dan beragam (Gambar 4). Hal ini menjadikan material batu alam semakin populer dalam dunia desain interior. Batu alam memiliki sifatsifat umum seperti: (a) Mempunyai kuat tekan dan kuat lentur yang tinggi, (b) Keras dan tidak mudah hancur, (c) Daya serap air relatif kecil, (d) Tahan terhadap pengaruh cuaca, dan (e) Tahan terhadap keausan. Jenis-jenis batu alam pun sangat bervariasi, beberapa diantaranya ialah marmer, travertine, granit, dan onyx. Kisaran harganya pun berbeda-beda, tergantung corak, warna, dan karakteristik batu.

Salah satu batu alam yang cukup potensial untuk bangunan dan elemen dalam ruang adalah granit. Karakteristik granit serta kelebihan dan kekurangan baru granit diantaranya (Alfari, Shabrina, 2015): tahan lama; daya tahan tinggi; tahan cuaca; kedap udara; tidak mudah retak, lebih murah dari marmer; tahan goresan; sambungan nat lebih tipis; terkesan mewah; halus; mudah dibersihkan; variasi corak dan warna minim; lebih berat dari batu alam lain.

\section{Hasil dan pembahasan}

Dalam tahap programming dilakukan penjabaran karakteristik material, permasalahan, serta peluang yang ada. Sehingga ditemukan solusi untuk penerapan teknik upcycling dalam pemanfaatan waste material batu alam. Teknik yang diterapkan berfokus pada penyusunan waste material tersebut menjadi suatu lembaran baru dengan hasil pola (pattern) yang berbeda-beda karena menyesuaikan dengan ukuran serta warna dari waste material yang tersedia (Tabel 1).

Pada tahapan perumusan ide perancangan dihasilkan beberapa alternatif pattern susunan waste material dengan kombinasi ukuran dan warna (Gambar 5). Nantinya susunan waste yang berbentuk sebuah lembaran baru ini akan difungsikan sebagai
Tabel 1. Pengelompokan waste material batu alam berdasarkan bentuk dan ukuran

\begin{tabular}{lll}
\hline Bentuk & \multicolumn{1}{c}{ Simetris }
\end{tabular}

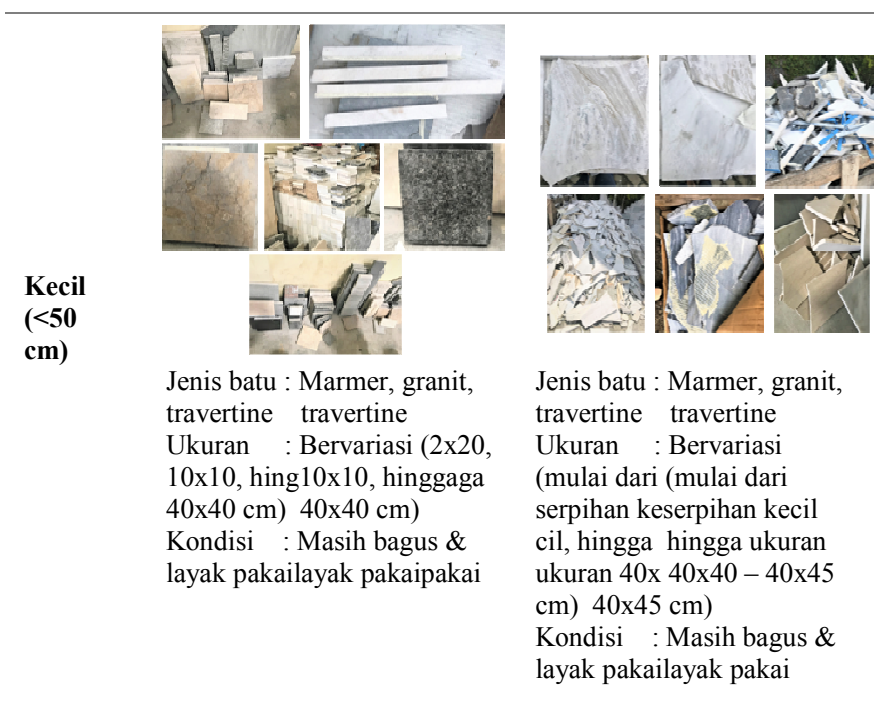
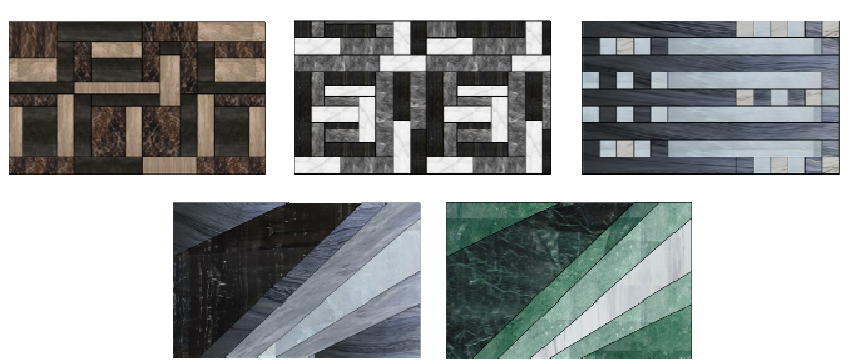

Gambar 5. Contoh alternatif susunan waste material batu alam
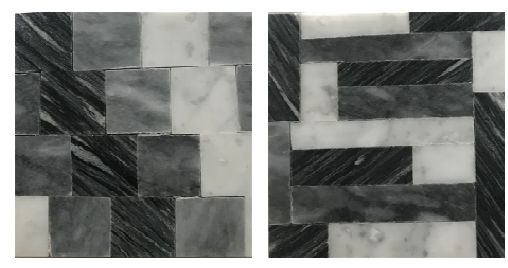

Gambar 6. Alternatif pattern terpilih yang direalisasikan menjadi prototype 
top table. Alternatif pola terpilih yaitu kombinasi waste material berukuran kecil dan bentuknya beraturan (simetris). Sehingga pattern yang dihasilkan akan berbentuk geometris (Gambar 6). Alternatif ini dipilih karena proses produksinya dapat menekan biaya \& pengerjaannya tidak rumit. Waste berbentuk simetris akan sangat menghemat biaya produksi karena lebih tidak memerlukan proses pemotongan dibanding dengan waste yang asimetris (harus dipotong dan dirapikan). Selain itu penggunaan waste berbentuk simetris juga dapat membantu meminimalisir terciptanya waste kembali. Hal ini dapat mengantisipasi agar nantinya harga jual produk upcycling tidak setinggi harga jual produk baru.

Konsep yang diangkat dalam perancangan ini adalah "Re-think, Re-assemble, Reduce". Rethink something new berarti memikirkan kembali potensi pengolahan waste material batu alam agar tidak terbuang (meminimalisir terciptanya waste kembali) dan dapat menaikkan nilainya. Reassemble waste berarti menyusun waste material batu alam sedemikian rupa agar dapat dipergunakan kembali dalam perancangan. Reduce cost berarti mengatur sistem produksi agar dapat mengurangi atau memotong biaya produksi, sehingga nilai jual produk tidak terlalu mahal. Keunikan batu alam juga akan ditonjolkan melalui perancangan ini, yaitu motif atau coraknya yang berbeda-beda. Keunikan inilah yang membuat tiap-tiap produk tidak akan sama persis an antara satu dengan yang lainnya.

Selanjutnya, berdasarkan konsep desain tersebut muncul beberapa batasan desain yang diterapkan dalam perancangan. Yang pertama yaitu penyusunan waste menjadi pattern dengan berdasar pada karakteristik waste (ukuran, bentuk, dan warna). Kedua, penerapan bentukan-bentukan yang geometris agar waste dapat digunakan secara maksimal dan meminimalisir terciptanya waste yang baru. Ketiga, rangka furniture berbentuk geometris karena harus kokoh dan mampu menahan serta menopang berat waste batu alam.

Konsep desain yang telah ditentukan kemudian ditransformasikan dalam proses desain. Batasan produk yang dirancangan merupakan produk untuk rumah tinggal \& terdiri dari 4 jenis, yaitu coffee table, side table, credenza, dan console table. Proses pengembangan desain diawali dengan visualisasi 3D, baik desain rangka meja maupun susunan waste material batu alam (Gambar 7).

Setelah membuat beberapa desain pada tahap pengembangan pertama, selanjutnya desain-desain ini dievaluasi dengan metode open group discussion untuk mendapat feedback dari pembimbing maupun pihak perusahaan PT. Gajah Mada Sukses Trirtunggal. Hasil feedback yang didapat menunjukkan bahwa desain awal masih belum sempurna, karena konstruksi serta material rangka meja tidak stabil dan perlu perbaikan. Feedback ini kemudian dijadikan landasan dalam perbaikan desain dalam pengembangan kedua.

Pada pengembangan desain kedua dihasilkan 3 buah coffee table, side table, credenza, dan console table, dengan total 12 produk furniture (Gambar 8). Dalam pengembangan kedua, sistem konstruksi dan material untuk rangka meja sudah disempurnakan. Setiap jenis funitur memiliki karakteristik ukuran top table yang sama, walaupun bentukan rangka kakinya berbeda-beda. Hal ini dimaksudkan agar nantinya proses produksi dapat mengarah ke arah mass production, dengan tetap menonjolkan keunikan corak batu alam yang berbeda-beda antara satu dengan yang lainnya. Setelah pengembangan desain kedua, dilakukan perwujudan prototype 4 furnitur dalam bentuk maket studi berskala 1:5 \& $1: 10$ (Gambar 9).

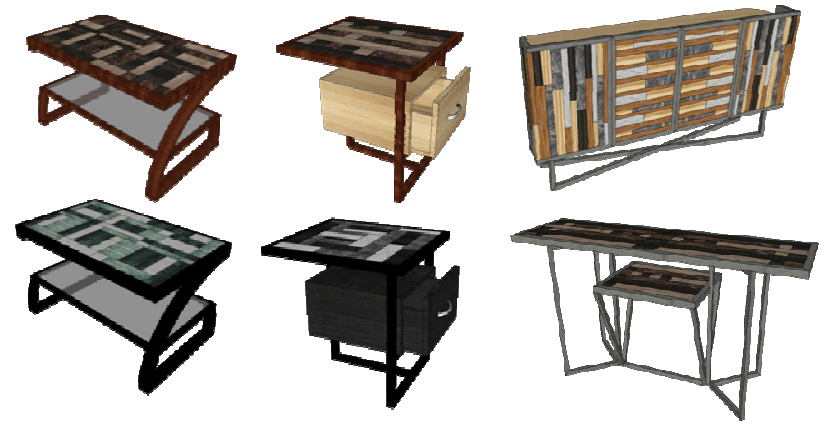

Gambar 7. Beberapa contoh visualisasi 3D produk perancangan

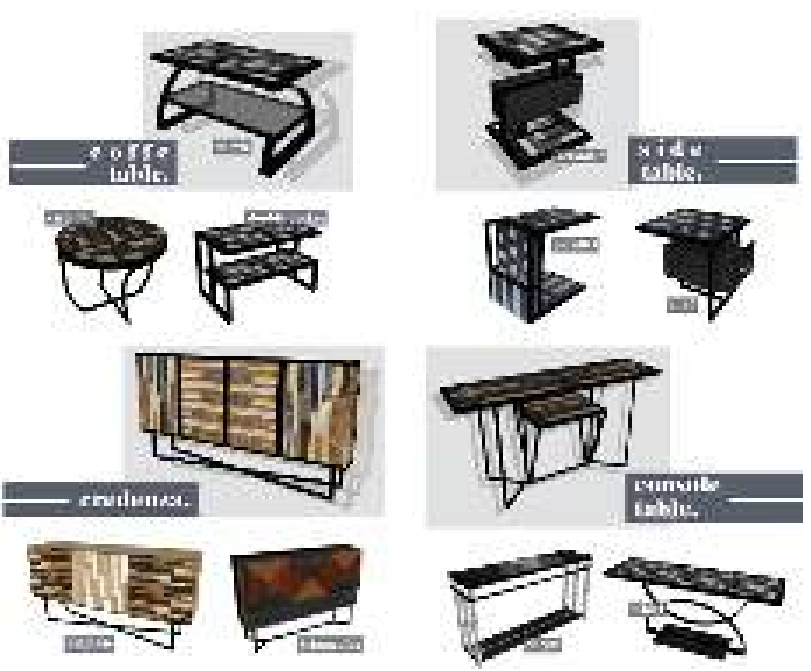

Gambar 8. Pengembangan desain kedua 


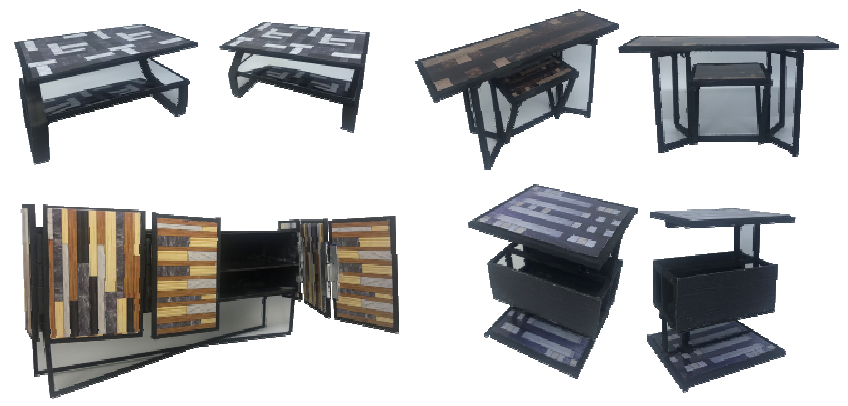

Gambar 9. Foto maket studi

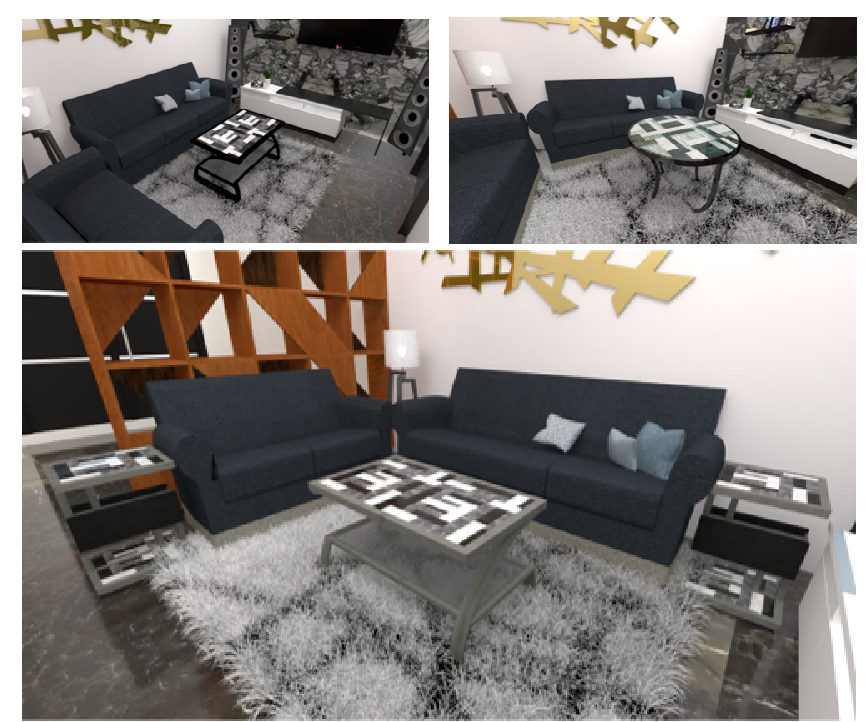

Gambar 10. Visualisasi produk dalam ruang
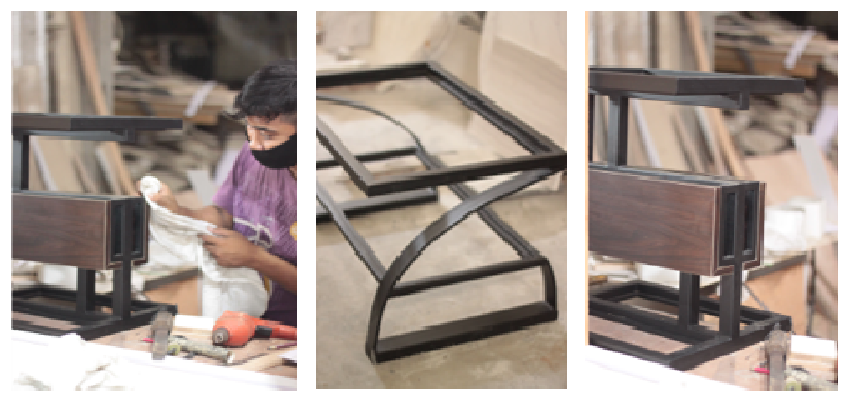

Gambar 11. Proses pembuatan rangka meja

Dalam tahap desain akhir dilakukan pemantapan desain produk dari hasil pengembangan desain kedua. Pemantapan dilakukan dengan cara membuat gambar kerja, visualisasi produk dalam ruang (Gambar 10), dan pemantapan material serta detil lainnya.

Desain yang terpilih untuk direalisasikan menjadi prototype 1:1 adalah coffee table dan side table. Proses produksi dibagi menjadi dua tahapan besar yang dilaksanakan di tempat terpisah. Pembuatan rangka meja dilakukan di salah satu mitra perusahaan interior di Surabaya, sedangkan proses pembuatan top table dan perakitan dilakukan di PT. Gajah Mada Sukses Tritunggal.
Rangka meja terbuat dari bahan besi hollow dengan finishing cat hitam doff / matte (Gambar 11). Tujuan penggunaan finishing doff karena jika tergores, goresan pada cat doff akan lebih tidak terlihat dibanding cat glossy. Setelah proses pembuatan rangka meja selesai, selanjutnya rangka akan dibawa ke PT. Gajah Mada Sukses Tritunggal untuk penyesuaian ukuran \& perakitan.
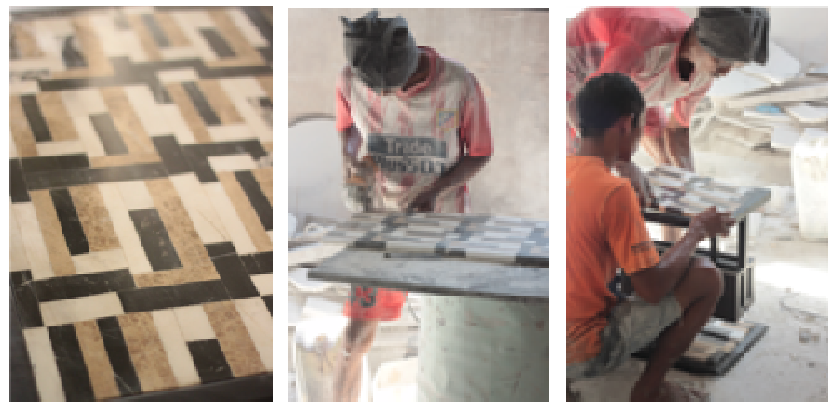

Gambar 12. Proses pembuatan top table

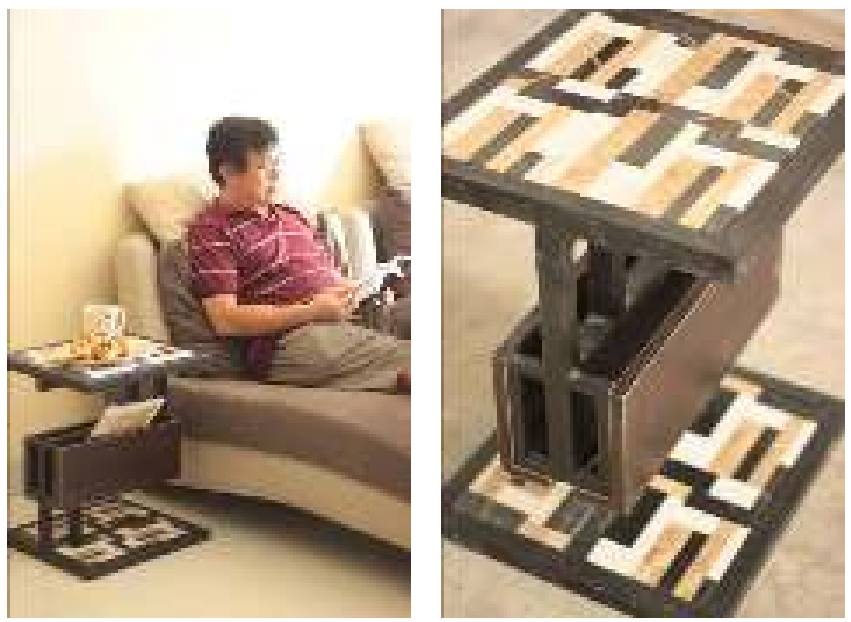

Gambar 13. Dokumentasi produk side table
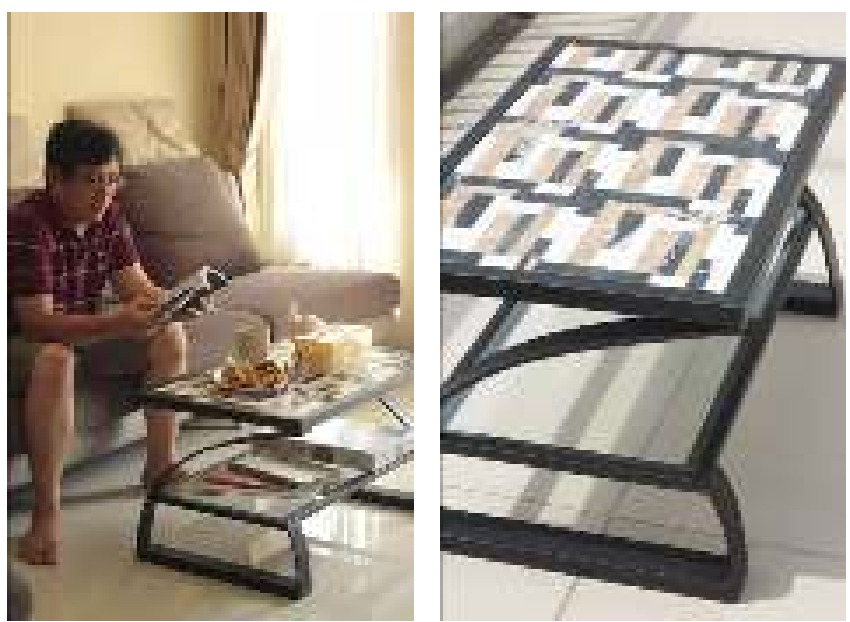

Gambar 14. Dokumentasi produk coffee table 


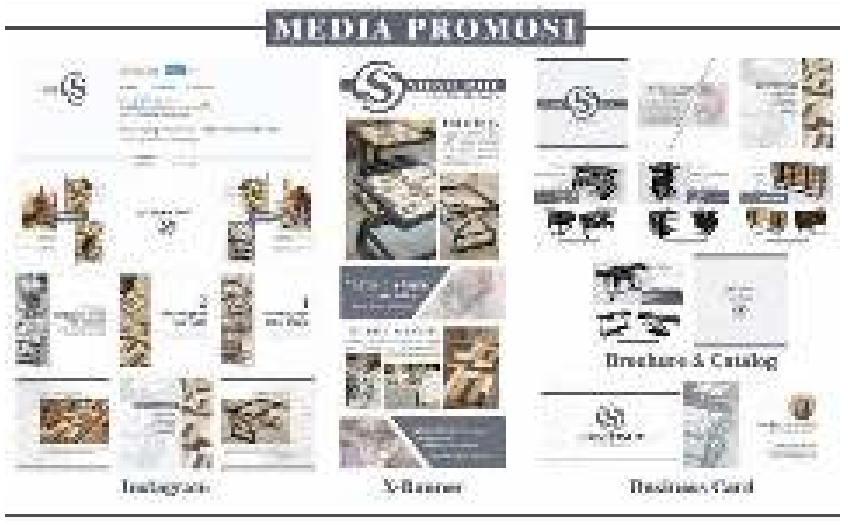

Gambar 15. Beberapa media promosi brand STONEFINITE

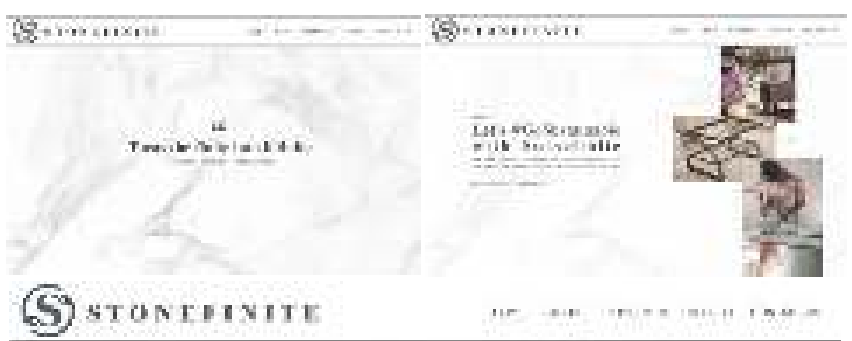

notsin

Inuvative \& transfirmative

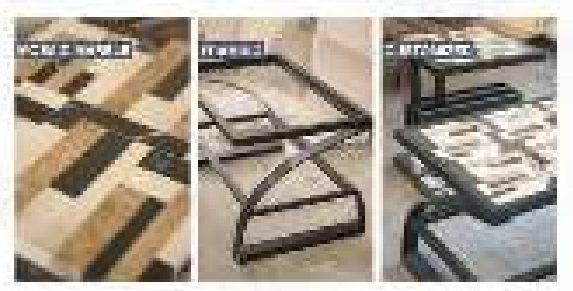

Gambar 16. Tampilan awal website STONEFINITE

Top table terbuat dari waste material batu alam yang disusun seperti mosaik. Proses pembuatan berjalan berurutan, yaitu: pemilihan batu, pengamplasan, penyususan batu dan pemberian resin 3314 , lalu pemasangan net dan proses pengeringan. Setelah itu dilakukan proses perakitan / pemasangan top table ke rangka meja. Top table dipasang tanpa bahan perekat apapun, sehingga dapat dilepas pasang (Gambar 13).

Proses validasi dilakukan untuk mengetahui apakah produk sudah layak untuk dipasarkan. Proses ini dilakukan dengan metode colleague \& common people review dan expert review. Metode colleague \& common people review dilakukan untuk mendapat feedback / saran dari orang lain sebagai user maupun pembeli. Sedangkan expert review digunakan untuk mendapatkan feedback dari orang yang ahli dalam bidangnya. Kedua metode ini dilakukan dengan cara open group discussion. Hasil validasi menunjukkan bahwa produk yang dihasilkan sudah layak untuk dipasarkan. Selain itu, produk juga mendapat feedback mengenai beberapa aspek yang dapat dikembangkan lebih lanjut untuk ke depannya

\section{Implementasi produk}

Produk yang telah dihasilkan dalam perancangan ini selanjutnya dipersiapkan untuk proses pemasaran (launching) ke publik. Mula-mula dilakukan pembuatan branding untuk menggambarkan identitas usaha yang akan dijual. Brand yang ditetapkan untuk usaha ini ialah STONEFINITE, yang terbentuk dari kata stone dan infinite. Penggabungan kedua kata tersebut bertujuan untuk menekankan bahwa material sisa potongan batu alam (stone) yang tampaknya sudah tidak berguna dan tidak dapat difungsikan kembali, nyatanya dapat diubah dan disusun menjadi suatu produk baru yang tidak terbatas (infinite) dan memiliki nilai guna kembali. Karena itulah motto dari brand ini adalah "Turns the finite into infinite" dengan menerapkan prinsip Rethink, Reduce, Reassemble.

(S) $\sin$ Rotiti

$$
\text { choose gour furniture }
$$
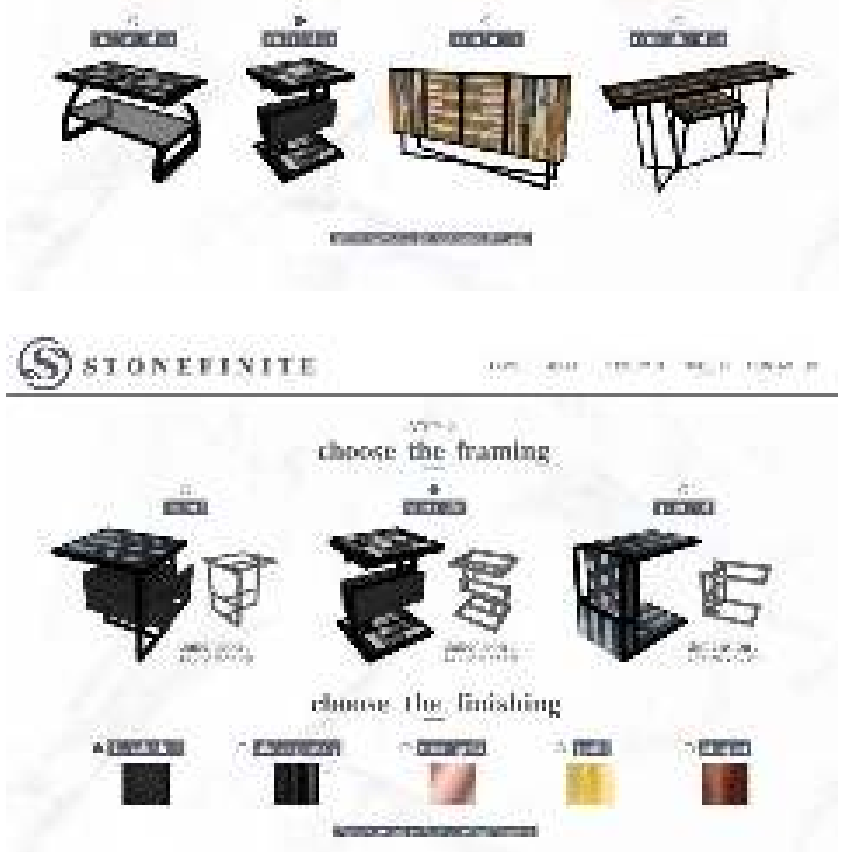

Gambar 17. Tampilan untuk pemilihan furnitur pada website STONEFINITE 
Langkah selanjutnya adalah melakukan launching produk melalui media promosi (Gambar 15). Proses launching akan digencarkan secara online. Sehingga perlu desain website yang komunikatif dan memudahkan pengguna untuk berbelanja langsung melalui website.

Website STONEFINITE dirancang sedemikian rupa dengan fitur-fitur yang memudahkan pengguna atau pembeli untuk berbelanja produk secara online. Contohnya yaitu: pengguna dapat memilih produk secara custom pada website, mulai dari rangka meja hingga pilihan mosaik batu alam. Selain itu pengguna juga akan mendapat visualisasi 3D produk yang akan dibeli.

\section{Penutup}

Waste material batu alam dapat diaplikasikan dalam perancangan furnitur, khususnya sebagai top table. Dengan pemahaman yang mendalam akan karakteristik waste material batu alam, ditemukan bahwa waste ini memiliki keunikan corak dan bentuk yang beragam, sehingga pola mosaik yang dihasilkan tidak akan sama persis satu dengan yang lainnya. Karakteristik inilah yang menjadi titik kelebihan dan mampu memberikan estetika tersendiri. Walaupun produk ini merupakan produk upcycling, kualitas yang dihasilkan sangat baik dan sudah mampu untuk dipasarkan ke publik.

Untuk perancangan kedepan dapat dilakukan eksperimen lebih lanjut mengenai penggabungan bentukan-bentukan waste batu alam yang lainnya dan teknik penggabungan waste. Pengembangan juga dapat dilakukan dengan mengeksplorasi potensi waste untuk diterapkan pada elemen interior maupun produk interior lainnya selain top table. Kualitas produk harus tetap terjaga, sehingga perlu dilakukan kontrol dalam setiap proses produksi, khususnya saat proses penggabungan waste batu alam.

Tulisan ini disusun berdasarkan penelitian terapan yang merupakan bagian dari "Service-Learning and Design Thinking in Solid Waste Recycling and Reuse Projects" yang didanai oleh United Board for Christian Higher Education in Asia. Atas subsidi pendanaan dalam pelaksanaan penelitian ini disampaikan terimakasih. Terima kasih juga disampaikan kepada Direktur PT. Gajah Mada Sukses Tritunggal, yang telah memberi kesempatan untuk melakukan kerja praktek dan melakukan eksperimen mengolah solid waste batu alam. Terimakasih berikutnya disampaikan Kepala Divisi Produksi PT. Gajah Mada Sukses Tritunggal, yang telah membimbing teknis eksperimen produksi mosaik batu alam.

\section{Daftar Pustaka}

Andreani, A. P., \& Prasetya, R. D. (2019). Petrified Wood: Karakteristik dan Aplikasinya dalam Bidang Desain Produk. Jurnal Rekarupa, 5(2).

Alfari, Shabrina. (2015). Granit sebagai bahan bangunan. Diakses pada 10 Maret 2020, dari https://www.arsitag.com/article/granit-sebagai-bahanbangunan

Ali, N. S., Khairuddin, N. F., Abidin, S. Z. (2013). Upcyling: Reuse and recreate functional interior space using waste materials. Paper dipresentasikan di International Conference of Engineering and Product Design Education.

Noorwatha, I. K. D., Ika, I. W. B., Tiaga, I. N. A. (2017). Studi materiality dalam aplikasi material upcycle pada desain interior. Dimensi Interior, 15(1), 1-6.

Plattner, Hasso. (2010). An introduction to design thinking. The Hasso Plattner Institute of Design at Stanford, Palo Alto, California, United States.

Sinai, Mina. (2017). Upcycling vs. recycling. Diakses pada 6 Maret 2020, dari https://recyclenation.com/2017/02/upcycling-vs-recycling/

Sutanto, Jessica. (2017). Upcycle Municipal Solid Waste Menjadi Wadah Modular Serbaguna untuk Anak-anak (Studi Kasus: Kota Surabaya). Undergraduate Thesis, Universitas Kristen Petra, 2017. Diakses dari https://dewey.petra.ac.id/catalog/digital/detail?id=40927

Wardani, Laksmi Kusuma. (2010). Perancangan furnitur perkantoran (proses desain, manufaktur, distribusi, dan konsumsi). Dimensi Interior, 8(1), 29-37. 